monozygotic twins reared apart is) and care should be exercised when trying to generalise about it.

The Royal Free Hospital

BISA HAEGER

Pond Street

London $\mathrm{NW} 2 \mathrm{2QG}$

\section{Dexamethasone Suppression Test}

SIR: I refer to the review article by Braddock on the dexamethasone suppression test (DST) (Journal. April 1986, 148, 363-374), with particular respect to nonspecific factors which might affect nonsuppression. I feel the omission of the effects of caffeine merits updating.

Uhde et al (1985) studied 22 normal volunteers and depressed patients (diagnostic criteria not specified). The DST consisted of dexamethasone $1 \mathrm{mg}$ at $11 \mathrm{pm}$ and a $4 \mathrm{pm}$ cortisol sample. Analysis was by radioimmunoassay. All subjects were given a single blind placebo controlled challenge of $480 \mathrm{mg}$ caf feine (equivalent to about 4 cups of filtered coffee) between 2 and $2.30 \mathrm{pm}$. Caffeine was found to increase the mean post-dexamethasone cortisol value from 2.3 to $5.3 \mu \mathrm{g} / \mathrm{dl}(P<0.001)$. For both volunteers and patients, when using the $5.0 \mu \mathrm{g} / \mathrm{dl}$ standard cut-off point, non-suppression occurred in $14 \%$ on placebo and $36 \%$ on caffeine. This dose of caffeine is not unusual when compared to the average daily consumption (Gilbert et al, 1976), and indeed in psychiatric patient populations more caffeine may be used (Galliano, 1982). In addition, depressed patients in particular may actually increase consumption of caffeine as a result of their illness (Greden et al, 1978; Neil et al, 1978). Caffeine therefore should be added as an additional non-specific factor which might affect non-suppression.

Institute of Psychiatry

Malcolm Bruce

De Crespigny Park

London SES $8 A F$

\section{References}

Galliano, S. J. (1982) Caffeine consumption in psychiatric patients. MPhil Thesis University London (Unpublished)

Gilbert, R. M. Marshman, J. A. \& Schwieder, M. (1976) Caffeine content of beverages as consumed. Canadian Medical Association Journal, 114, 205-208.

Grfden, F. J., Fontaine, P., Lubetsky, M. \& Chambertine, K (1978) Anxiety and depression associated with caffeinism amon psychiatric inpatients. American Journal of Psychiatry. 135, 963-966.

Neil, J. F., Himmelhoch, J. M., Mallinger, A. G. Mallinger, 2. HANIN, I. (1978) Caffeine complicating hypersomnic depressive episode. Comprehensive Psychiatry, 19, 377-385.

Uhde, T. W., Bierer, L. M. \& Post, R. M. (1985) Caffeine-induced escape from dexamethasone suppression. Archives of General Psychiatry, 42, 737-738.
Is Hysteria (Conversion Reaction) Still Alive?

SIR: The article by Shalev and Munitz entitled Conversion Without Hysteria: A Case Report and Review of Literature brings out the controversy which exists around the diagnosis of hysteria (Journal, February 1986, 481, 198-203).

My experience in a psychiatric hospital in India in a semi-urban area is that there is a well defined group of patients who can be given a diagnosis of hysteria. We have described the clinical features of such a group of 276 patients (Subramaniam et al, 1980). Similar patients are very common in most of the psychiatry clinics in India. The following are the common clinical features: presence of physical symptoms, more often monosymptomatic, in motor or sensory system without any organic basis; premorbid hysterical personality traits; age of onset of symptoms before 20 years; more among females; dramatisation of symptoms with belle indifference; presence of some unconscious conflict not necessarily sexual in nature and complete recovery with psychoanalytically oriented psychotherapy. Any physical symptom in the absence of an organic basis should not be considered hysterical. If this is established, it is likely that hysteria or conversion reaction will continue in spite of the obituaries pronounced on it by Slater and others.

Christian Medical College

Abraham Verghese

Vellore, India

\section{Reference}

Subramaniam, D.. Subramaniam, K. Devaky, M. N. \& Verghese, A. (1980) A clinical study of 276 patients diagnosed as suffering from hysteria. Indian Journal of Psychiatry, 22, 63-68.

\section{On Serious Violence During Sleep-walking}

SIR: Drs Oswald and Evans (Journal, December $1985,147,688-691$ ) presented some interesting material on somnambulism, including a case of a criminal act committed in sleep. We report another case.

Case report: A young man stayed overnight at his mother's. In the middle of the night he was awakened by an unpleasant dream in which his mother criticised and attacked his girlfriend. He sat up and dressed, with the dream going on in his head, but aware of where he was. Suddenly he got the thought-as if a voice in his head told him-that he should threaten his mother not to be so derogatory and aggressive to his girl-friend. So he went to get a hammer in the basement and went to his mother's bed. Just as he was about to wake her she moved in her sleep. To his surprise he hit her again and again with the hammer without a conscious thought, until after a while he 